\title{
Anterior Staphyloma following Xerophthalmia-A case report
}

\author{
Dr. Gaining Lulu Kamei ${ }^{1}$, Dr. Yumnam Chingsuingamba Meitei ${ }^{2}$ \\ ${ }^{1,2}$ (Department of Ophthalmology, Regional Institute of Medical Sciences, Imphal,Manipur,India)
}

\begin{abstract}
A major preventable cause of childhood blindness worldwide is Xerophthalmia caused by Vitamin A deficiency(VAD). Currently, it is estimated that there are about 1.5 million blind children in the world, of whom one million live in Asia. Keratomalacia, the last and most severe sign of Xerophthalmia may progress either to Phthisis Bulbi or Staphyloma, which leads to blindness and loss of the eye. Children with severe malnutrition and Measles are at high risk of Vitamin A deficiency. Xerophthalmia complicating into Staphyloma, the most severe complication, is rarely reported. We report a case of a 5 years old girl with history of Protein Energy Malnutrition (Kwashiorkar) presenting with swelling, excessive lacrimation, discharge from the right eye and corneal opacity in the left eye since 2 years. On examination right eye showed Anterior Staphyloma with no perception of light; left eye showed corneal opacity with vision of finger counting close to face. From the clinical and ophthalmological findings, the patient was diagnosed with anterior staphyloma following Xerophthalmia. Evisceration was done for the right eye.In developing countries like India where there is relative inaccessibility to health services prevention, early detection and prompt treatment is the only way to prevent Xerophthalmia and its complications.
\end{abstract}

Key-words: Anterior Staphyloma, Evisceration, Keratomalacia ,Xerophthalmia

\section{Introduction}

Vitamin A deficiency remains a major cause of paediatric ocular morbidity. Currently, it is estimated that there are about 1.5 million blind children in the world, of whom one million live in Asia. ${ }^{1}$ Each year there are half a million new cases, $70 \%$ of which are due to VAD which leads to Xerophthalmia. ${ }^{2}$ While VAD can occur at any age, the group at risk of blindness is children in the preschool age group, from 6 months to 6 years of age especially if their mothers had VAD in pregnancy or during breastfeeding. ${ }^{3}$ Vitamin A is an essential nutrient as it cannot be synthesised by the body ${ }^{4}$ and is required for normal functioning of the visual system, maintenance of cell function for growth, epithelial integrity, production of red blood cells, immunity and reproduction. ${ }^{5}$ Literatures on prevalence or incidence of Anterior Staphyloma following Xerophthalmia are hard to find. This may be due to under reporting following poor socioeconomic condition of the parents, poor awareness on seeking medical attention, neglected malnourished children and high mortality amongst children afflicted with VAD and Protein energy malnutrition (PEM) due to its complications. In a follow up study done in 216 Vitamin A deficient children hospitalised in Hyderabad, Krishnakumari M and Vijayaraghavan K observed only 2 cases of anterior Staphyloma following Xerophthalmia. ${ }^{6}$ In the case under study the patient was diagnosed with Anterior Staphyloma following Xerophthalmia after history and clinical examinations.

\section{Case History}

A 5 years old girl was admitted with complaints of a protruding right eyeball with lacrimation and white patch on left eye for 2 years. She was treated for PEM (Kwashiorkar) 2 years back. Her PEM was complicated with Keratomalacia and Xerophthalmia of both eyes. She was treated but she failed regular follow up as advised.

On physical examination the patient was average Indian build, uncooperative and apathic. General and systemic examinations were within normal limit. Ocular examination of right eye revealed a negative perception of light,bulging eyeball with congested lustreless and thickened conjunctiva; cornea was opaque, ectatic, distorted with smooth surface. Peripheral vascularisation with adherent iris was seen. Fundus and other details could not be visualised. The left eye visual acuity was finger counting close to face. An irregular shaped non vascularised nebulomacular corneal opacity from 4 to 80 ' clock position near the limbus with its inner margin $0.8 \mathrm{~mm}$ from the pupillary border( Fig 1) was seen. Fundus and rest of the ocular examination of left eye were normal.

She was diagnosed with Anterior Staphyloma right eye with nebulomacular corneal opacity left eye following Xerophthalmia.

Routine investigations were within normal limits.

The right blind eye had unsightly appearance and a protruding eyeball which was vulnerable to bleeding and/or infections from minor trauma. The eye was eviscerated under general anaesthesia to prevent these complications and for improved cosmesis(Fig 2).A prosthetic shell was implanted after 6 weeks to improve the appearance. 


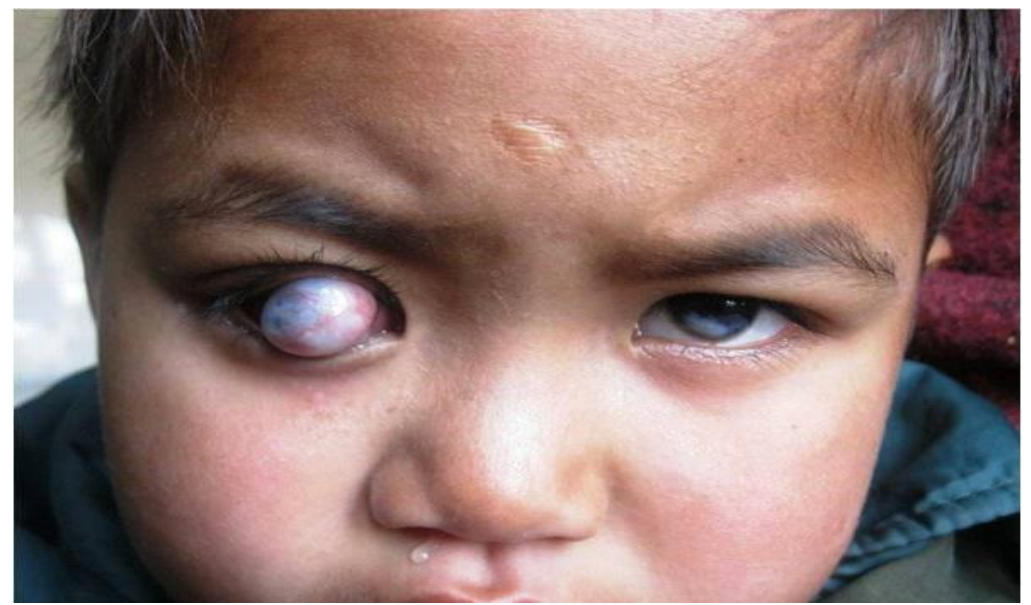

Fig.1.Showing right anterior staphyloma and left nebulomacular corneal opacity

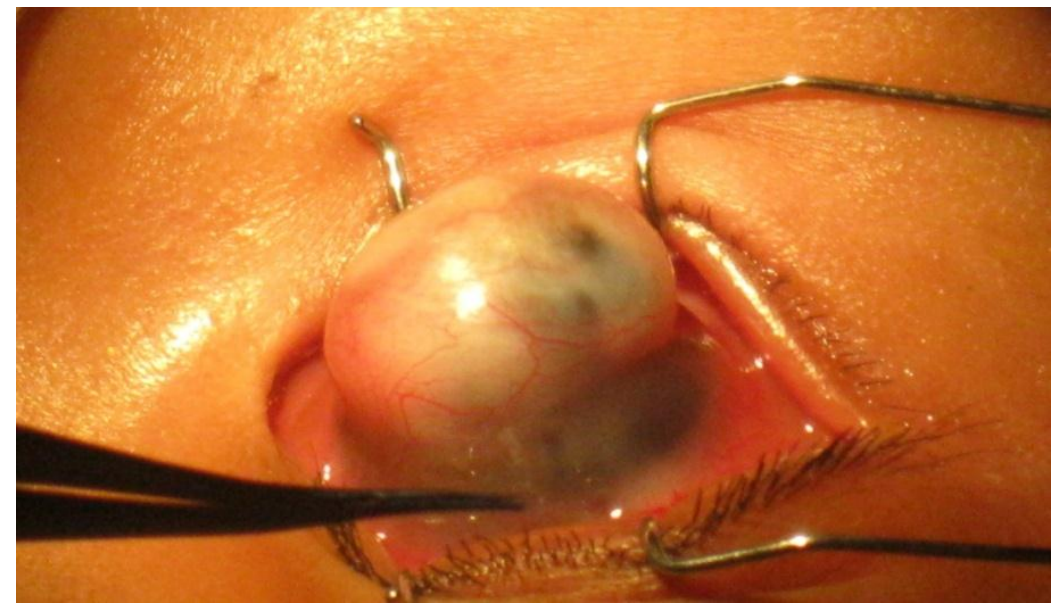

Fig.2.Showing evisceration of right eye

\section{Discussion}

Protein-calorie malnutrition affects every tissue and every cell in the body and is rampant in the preschool children, especially in the developing nations. VAD increases vulnerability to a range of illnesses including diarrhoea, measles, and respiratory infections and vice versa. ${ }^{7,8}$ Vitamin A plays a vital role in the cellular growth and differentiation. The maintenance of integrity of epithelial cells and the metabolic functions of sub cellular membranes is an important function of Vitamin-A. Dysfunction of corneal and conjunctival epithelial cell differentiation governed by vitamin A results in graded abnormalities in the ocular surface ranging from punctate epithelial erosions to corneal perforation. ${ }^{9,10}$ It can be initially misdiagnosed since the signs are easily mistaken for epithelial erosions seen in keratoconjunctivitis sicca or exposure keratopathy. Without treating the underlying vitamin A deficiency, these ocular surface conditions are progressive and refractory to lubricating therapy or even surgical intervention. Keratomalacia (X3B) or corneal melting which is the last and most severe sign is a medical emergency as patient go blind within 24-48 hours unless treated with Vit.A. ${ }^{7,11}$ Xerophthalmia of the X3B grade ( Keratomalacia) may progress to perforation with extrusion of intraocular contents leading to permanent distortion or loss of globe ${ }^{12}$;or phthisis bulbi or pseudocornea leading to anterior staphyloma. ${ }^{13}$

\section{Conclusion}

Given the potential rapidity of Xerophthalmia ( Keratomalacia X3B) to cause blindness and the relative inaccessibility of health services to those at greatest risk, prevention is more important than treatment of VAD or Xerophthalmia. Prevention, early detection and prompt treatment is the only way to prevent Xerophthalmia and its complications. 


\section{References}

[1] Hornby SJ, Xiao Y, Gilbert CE, Foster A, Wang X, Liang X, et al. Causes of childhood blindness in the People's Republic of China: results from 1131 blind school students in 18 provinces. Br J Ophthalmol 1999Aug; 83(8):929-932.

[2] Thylefors B. Present challenges in the global prevention of blindness. Aust N Z J Ophthalmol 1992May; 20(2):89-94.

[3] 3.Gilbert C, Duran HLA, Kotiankar S, McGavin M. Prevention of childhood blindness teaching set. London: International Centre for Eye Health (ICEH); 2007.

[4] Bates CJ. Vitamin A. Lancet 1995 Jan7; 345(8941):31-5

[5] Sommer A,West KP. Vitamin A deficiency: health, survival, and vision. New York: Oxford University Press;1996.

[6] Menon K, Vijayaraghavan K. Sequelae of severe Xerophthalmia- a follow-up study. Am J Clin Nutr 1980 Feb; 33(2):218-20.

[7] Sommer A, Katz J, Tarwotjo I. Increased risk of respiratory disease and diarrhea in children with preexisting mild vitamin A deficiency. Am J Clin Nutr 1984 Nov; 40(5):1090-5.

[8] Rice AL,West KP Jr, Black RE.Vitamin A deficiency. In: Ezzati M, Lopez AD, Rodgers A, Murray CJL, editors. Global and Regional Burden of Disease Attributable to Selected Major Risk Factors. Switzerland :World Health Organization;2004.p211-256.

[9] Heinz C, Steuhl KP, Meller D. Corneal perforation associated with Vitamin A deficiency. Ophthalmologe 2004 Jun; 101(6):614-7.

[10] Smith J, Steinemann TL. Vitamin A deficiency and the eye. Int Ophthalmol Clin 2000; 40(4):83-91.

[11] Sommer A. Nutritional Blindness: Xerophthalmia and Keratomalacia. New York: Oxford University Press;1982.

[12] Sommer A. Field Guide to the Detection and Control of Xerophthalmia.2nd ed. Geneva: WHO; 1982.

[13] Indicators for assessing vitamin A deficiency and their application in monitoring and evaluating intervention programmes. WHO/NUT/94.1,1994. 